\title{
REMANUFACTURING PROCESS AND ITS CHALLENGES
}

\author{
M. Andrew-Munot ${ }^{1 *}$ and R.N. Ibrahim ${ }^{2}$ \\ ${ }^{1}$ Faculty of Engineering, Universiti Malaysia Sarawak, \\ 94300 Kota Samarahan, Sarawak, Malaysia \\ E-mail: ammagdal@feng.unimas.my \\ Phone: +6082-583300, Fax: +6082-583410 \\ ${ }^{2}$ Faculty of Engineering, Monash University, Australia, \\ Building 31, Monash University, Victoria 3800, Australia \\ E-mail: Raafat.Ibrahim@monash.edu \\ Phone: +613990 51982
}

\begin{abstract}
Recently, the remanufacture of used products has become an important production activity for many companies. This is motivated primarily by strict environmental regulations, increasing customers' awareness of environmental issues, and economic benefits. Remanufacturing is an industrial process that involves four key processes: inspection/grading, disassembly, component reprocessing, and reassembly/testing. It is established that the presence and interactions of several unique characteristics within the remanufacturing systems implicate subsequent key processes. These unique characteristics present challenges to production planning and control activity in any remanufacturing system. Consequently, it is imperative that these characteristics are properly considered in any production planning and control activity.
\end{abstract}

Keywords: Used products; remanufacturing; unique characteristics.

\section{INTRODUCTION}

Recently, the remanufacture of used products (remanufacturing) has become an important part of the normal production activity for many companies (Guide Jr, Jayaraman \& Srivastava, 1999; Guide Jr, 2000; Aras, Boyaci, \& Verter, 2004; Ferrer \& Swaminathan, 2009; Schulz \& Ferretti, 2011). This trend has been motivated by three emerging factors: strict environmental regulations (Directive 2000/53/EC; Directive 2002/96/EC; Japanese Home Appliance Law, 2001), increasing customers' awareness of green environmental issues (Gungor \& Gupta, 1999; Ferrer \& Whybark, 2000; McGovern \& Gupta, 2004; Georgiadis \& Besiou, 2010), and economic benefits (Rogers \& Tibben-Lembke, 1999; Dowlatshahi, 2000; Maslennikova \& Foley, 2000; Giuntini \& Gaudette, 2003). The automotive sector in particular has a strong history of remanufacturing (Seitz, 2007), where numerous auto parts have been remanufactured and resold as spare parts (Steinhilper, 1998). Pioneering companies, such as Fuji Xerox Australia (Fuji Xerox Australia, 2007), Xerox Europe, and Kodak (Guide Jr., Teunter, \& van Wassenhove, 2003a), have also expanded their core business operations to include remanufacturing. In addition, remanufacturing is gaining scientific significance in industries that include flat screen monitors (Franke, Kernbaum, \& Seliger, 2006), single use-devices for hospitals, such as wheelchairs and hearing aids (Srivastava, 2004; Rudi, Pyke, \& Sporsheim, 2000), cellular phones (Guide Jr., Jayaraman, \& Linton, 2003b), and truck tires (Lebreton \& Tuma, 2006). 
Any manufactured product, device or mechanical system can be remanufactured. The major requirements are discarded used products with lower costs involved in the materials and reprocessing of the components than the market value of the remanufactured items (Lund, 1984a). Moreover, according to Hauser \& Lund (2003) used products must be: (i) durable products, (ii) products that fail functionally, (iii) standardized products with interchangeable parts, (iv) products with high remaining value-added, (v) products with low acquisition costs, (vi) products with stable technology, and (vii) there must be customer awareness of the remanufactured version. The sources of used products are either from waste or the market stream (Guide Jr. \& Wassenhove, 2001; Jayaraman, 2006). The waste stream used products are products that are no longer useful. These includes cars that have been damaged during accidents and sent to a wrecking facility, or malfunctioning refrigerators that are sent to a third party product recovery facility. Market stream used products are products that are still useful, but that are no longer needed by their owners. An example is an old model of a cellular phone, which is traded-in for a newer model with advanced features.

Remanufactured products are sold in primary and secondary product markets. Within the primary product market, remanufactured products are perfect substitutes for new products (Souza \& Ketzenberg, 2002). This refers to original equipment manufacturer (OEM) used products, which are remanufactured to a quality standard that is as good as new at the OEM's remanufacturing facility. These cheaper remanufactured products are sold in the same market as the new products (Ferrer \& Swaminathan, 2009). For the secondary product market, remanufactured products are popular amongst those customers who may have financial restrictions. In this case, remanufactured products are usually produced by third-party remanufacturers who harvest the economic benefits of remanufacturing. Usually, the remanufactured products (e.g., computer systems, auto components, and office equipment) have a lower quality standard and price than newly manufactured products (Ayres, Ferrer, \& van Leynseele, 1997; Ferrer, 1997). This article describes and examines in detail the three key stages of the remanufacturing process, to identify some of their unique characteristics.

\section{REMANUFACTURING PROCESS}

Remanufacturing refers to an industrial process in which used products are transformed into remanufactured products with a quality condition that is typically as good as new products (Lund, 1984b). Referring to Figure 1, the remanufacturing process normally consists of four key stages: inspection/grading, disassembly, component reprocessing, and reassembly/testing.

\section{Stage 1: Inspection/Grading process}

During this stage, used products are inspected for their quality condition to assess their remanufacturability status. This process usually involves a complete visual inspection, where inspection times are similar for the same type of used products that originate from the same source (e.g., used cellular phones from the market stream). However, between the waste and market streams, the waste stream could generate used products with a high variability of quality condition; thus, this could result in differing inspection times for each unit of used product. Furthermore, used products that originate from the waste stream probably require a longer inspection time and special inspection tools. 
After the inspection process, used products are considered either as scrap or as remanufacturables. The scrap products are either disposed of or sold to scrap brokers, whereas remanufacturables are sent to the disassembly/inspection process. The proportion of used products graded as remanufacturables (also known as the inspection yield) varies from one batch to another owing to the uncertain quality condition of the used products. Despite their origins, remanufacturables can be classified further into multiple quality groups, where the best quality group should be given the highest priority for remanufacturing (Aras, Verter, \& Boyaci, 2006; Aras et al., 2004). Furthermore, the waste stream, which has high variability of quality condition, could result in more quality groups than the market stream.

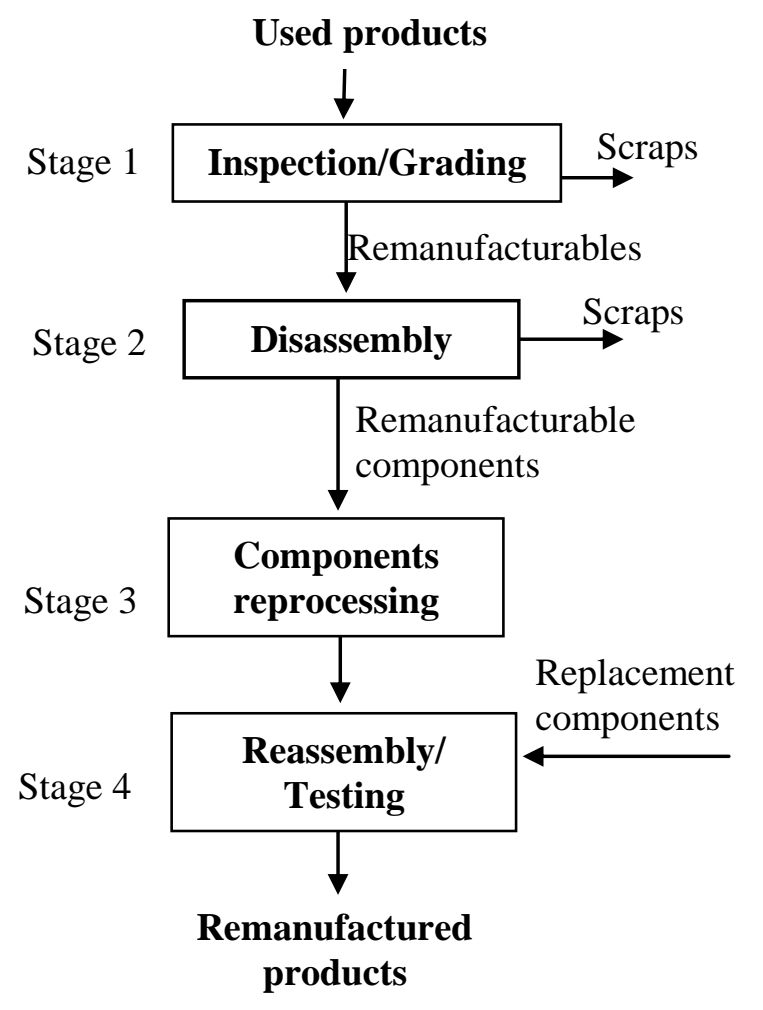

Figure 1. Key remanufacturing process and material flows (developed based on remanufacturing process described in Lund (1984b)).

\section{Stage 2: Disassembly/inspection process}

During this process, a remanufacturable item would be disassembled into its modules, which are further disassembled into individual components. This process usually involves general-purpose tools such as power drills, although robotic arms may be necessary for the disassembly of complex used products (Steinhilper, 1998) or hazardous parts (Zussman \& Seliger, 1999). Regardless of the origins and quality groups, disassembly times are similar for the same type of remanufacturables. Generally, disassembly time depends on the complexity of the product structure. Remanufacturables with a simple product structure (Figure 2(a)) require shorter disassembly time than those with a complex product structure (Figure 2(b)). Another factor that affects the disassembly time is the labor skill assigned for the disassembly process, where highly skilled labor (e.g., robotic arms) could reduce disassembly times. 
Depending on the product structure and volume, disassembly (of remanufacturables) and inspection of the constituent components can take place either simultaneously or sequentially. For high-volume remanufacturables with simple product structure, the disassembly and inspection processes could take place simultaneously. Similarly, for low-volume remanufacturables with complex product structure, the disassembly and inspection processes could take place simultaneously. However, for high-volume remanufacturables with complex product structure, the disassembly and inspection processes usually occur sequentially in a two-stage disassembly line (Steinhilper, 1998).

$\mathbf{H}$ and $\mathbf{K}$ are end products.

$\mathbf{I}$ and $\mathbf{J}$ are constituent components of product $\mathbf{H}$.

$\mathbf{M}$ is a sub-assembly of product $\mathbf{K}$.

$\mathbf{L}, \mathbf{N}, \mathbf{O}$ and $\mathbf{P}$ are constituent components of product $\mathbf{K}$.

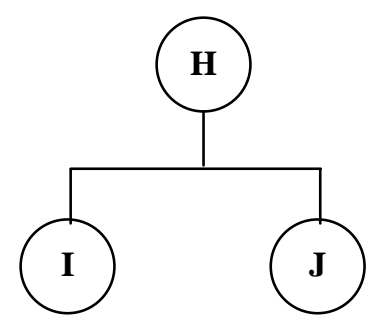

(a)

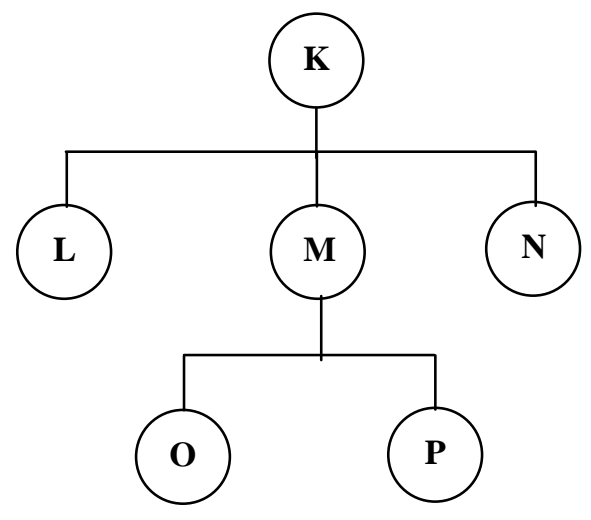

(b)

Figure 2: Examples of products with (a) a simple structure and (b) a complex structure.

After inspection, the constituent components are graded either as remanufacturables or as scrap. Scrap components need to be replaced and replacements can be ordered either from internal production lines (in the case of OEM remanufacturers) or from external sources (in the case of third-party remanufacturers). Replacement components are very important, particularly for the remanufacture-toorder strategy, whereby a customer sends used products (e.g., aircraft engines) for remanufacture and request that the same items be returned. Owing to the uncertain quality conditions (of remanufacturables), the proportion of constituent components (e.g., component $\mathbf{J}$ in Figure 2(a)) classified as remanufacturables, might also differ from one batch to another (henceforth, this proportion is termed the disassembly yield). Considering component $\mathrm{J}$, the disassembly yield for remanufacturables from the group of best quality would be higher than that from the group of worst quality. Furthermore, for the remanufacturables group of similar quality, the disassembly yield of remanufacturables originating from the market stream would be higher than that from the waste stream.

In addition, the quality condition of remanufacturable constituent components varies. Thus, it is necessary to classify them into multiple quality groups, where the group with the best quality is given the highest priority in remanufacturing. Moreover, it 
is also probable that remanufacturables originating from the waste stream would result in a greater number of quality groups than the market stream. Finally, regardless of the products' structure, product design also affects the disassembly yield (Ferrer, 2001). Products that are not designed for disassembly generate a lower disassembly yield than those that are; this is because of the potential for damage during disassembly.

\section{Stage 3: Reprocessing of remanufacturable constituent components}

This stage normally involves processes that include cleaning, repairing (e.g., machining worn-out holes), and surface finishing with the aim to restore the components to their original condition. The number of processes and time required to reprocess each component to its original condition, depends mainly on the components' quality group. For example, components from the best-quality group would probably require only cleaning and surface finishing, i.e., a simple process and short reprocessing time. However, components from the poor-quality group would perhaps require cleaning, repairing, and surface finishing; thus, involving a complex procedure and longer reprocessing time.

For components with a complex design, multiple repair steps (e.g., cutting, welding, and trimming) might be necessary in order to restore the components to their original condition. Conversely, some components (such as bulbs, electrical wires, or cellular phone casings) are merely replaced with new ones, because these components are non-repairable. In addition, the absence of a repair process could be the case for third-party remanufacturers, who may not equipped with the appropriate technology to repair components, particularly OEM used products.

\section{Stage 4: Reassembly}

This stage typically involves general-purpose tools for the reassembly of the constituent components into remanufactured products with simple structure. However, it may be necessary to use robotic arms for reassembly of constituent components into remanufactured products that have complex structures. The beginning of the reassembly process is influenced significantly by the completion of the preceding processes, i.e., the reassembly process is initiated only when all the relevant components (reprocessed and new) are available. Similar to the disassembly process, reassembly time can be improved by employing highly skilled workers.

\section{CHALLENGES}

It is highlighted that several unique characteristics are predominantly present within the remanufacturing environment. These unique characteristics are (i) uncertain quality condition of used products, (ii) variable inspection yields of used products, (iii) variable disassembly yields of constituent components, (iv) variable reprocessing efforts of constituent components, (v) multiple key remanufacturing stages with inter-dependency between stages, (vi) multiple types of constituent components, and (vii) matching and reassembly of the same set of constituent components into final products in a customerdriven environment.

These unique characteristics have also been mentioned in the literature (Guide Jr., Srivastava, \& Kraus, 1997a, 1998; Guide Jr., Srivastava, \& Spencer, 1997b, 1998, 1999; Fleischmann, Bloemhof-Ruwaard, Dekker, van der Laan, van Nunen, \& van 
Wassenhove, 1997; Guide Jr. \& Srivastava, 1997; Ferrer, 2003). Nevertheless, these works have failed to discuss the interactions and implications of these unique characteristics within each remanufacturing stage. Based on the earlier discussion, it is obvious that these unique characteristics, if not properly considered, would complicate production-planning activities within any remanufacturing systems. Therefore, it is very important that these unique characteristics are considered in any study on remanufacturing systems.

\section{CONCLUSION}

The remanufacture of used products has become an important production activity for many companies. The major reasons for this are strict environmental regulations, increasing customers' awareness of green environmental issues, and economic benefits. As an industrial process, remanufacturing aims to restore used products into products, which have the same quality condition as new products. The general remanufacturing process involves (i) inspection/grading, (ii) disassembly, (iii) component reprocessing, and (iv) reassembly/testing. In this paper, it has been established that the existence of several unique characteristics within the remanufacturing environment complicate the subsequent key processes. Undoubtedly, the existence and interactions of these unique characteristics would present challenges to production planning and control activity in any remanufacturing system. Accordingly, it is essential that these characteristics be considered properly in any production planning and control activity.

\section{ACKNOWLEDGEMENTS}

The authors would like to express their deepest gratitude and thankfulness to P.B. Lochert, H. Siajadi, D. Godamunne, V. Chippada, J. Dhanu, K. Thera, K. Anna, W. Sun, and M. Sawawi for their cooperation and support towards this project. Lastly, the authors would like to acknowledge the Malaysian Public Works Department (JPA) and Universiti Malaysia, Sarawak, (UNIMAS) for giving financial support towards this work.

\section{REFERENCES}

Aras, N., Boyaci, T., \& Verter, V. (2004). The effect of categorizing returned products in remanufacturing. IIE Transactions, 36(4), 319-331.

Aras, N., Verter, V., \& Boyaci, T. (2006). Coordination and priority decisions in hybrid manufacturing/remanufacturing systems. Production and Operations Management, 15(4), 528-543.

Ayres, R., Ferrer, G., \& van Leynseele, T. (1997). Eco-efficiency, asset recovery and remanufacturing. European Management Journal, 15(5), 557-574.

Dowlatshahi, S. (2000). Developing a theory of reverse logistics. Interfaces, 30, 143155.

European Parliament and The Council (2000) Directive 2000/53/EC - the "ELV" of 18 September 2000 on end-of life vehicles. Retrieved from http://ec.europa.eu /environment/ waste/elv_index.htm.

European Parliament and The Council (2003) Directive 2002/96/ EC of 27 January 2003 on waste electrical and electronic equipment (WEEE). Retrieved from 
http://www.environ.ie/en/Legislation/Environment/Waste/WEEE/

FileDownLoad, 613,en.pdf.

Ferrer, G. (1997). The economics of tire remanufacturing. Resources, Conservation and Recycling, 19(4), 221-255.

Ferrer, G. (2001). On the widget remanufacturing operation. European Journal of Operational Research, 135(2), 373-393.

Ferrer, G., (2003). Yield information and supplier responsiveness in remanufacturing operations. European Journal of Operational Research, 149(3), 540-556.

Ferrer, G., \& Swaminathan, J. M. (2009). Managing new and differentiated remanufactured products. European Journal of Operational Research, 2, 370379.

Ferrer, G., \& Whybark, D. C. (2000). From Garbage to Goods: Successful Remanufacturing Systems and Skills. Business Horizons, November-December, 55-64.

Fleischmann, M., Bloemhof-Ruwaard, J. M., Dekker, R., van der Laan, E., van Nunen, Jo. A. E. E., \& van Wassenhove, L. N. (1997). Quantitative models for reverse logistics: A review. European Journal of Operational Research, 103(1), 1-17.

Franke, C., Kernbaum, S., \& Seliger, G. (2006). Remanufacturing of flat screen monitors. in Innovation in Life Cycle Engineering and Sustainable Development, edited by Brissaud, D., Tichkiewitch, S. and Zwolinski, P. (Springer, Netherland, 2006), 139-152.

Fuji Xerox, Australia. (2007). Information extracted from FujiXerox, Retrieved from http://www.fujixerox.com.au/about/eco_manufacturing.jsp.

Georgiadis, P., \& Besiou, M. (2010). Environmental and economic sustainability of WEEE closed-loop supply chains with recycling: a system dynamics analysis. International Journal of Advanced Manufacturing Technology, 47, 475-493.

Giuntini, R., \& Gaudette, K. (2003). Remanufacturing: The next great opportunity for boosting US productivity. Business Horizons, November-December, 41-48.

Guide Jr., V.D.R., Jayaraman, V., \& Srivastava, R. (1999). The effect of lead time variation on the performance of disassembly release mechanisms. Computers \& Industrial Engineering, 36(4), 759-779.

Guide Jr., V. D. R. (2000). Production planning and control for remanufacturing: industry practice and research needs. Journal of Operations Management, 18(4), 467-483.

Guide Jr., V. D. R., \& Srivastava, R. (1997). Buffering from material recovery uncertainty in a recoverable manufacturing environment. The Journal of the Operational Research Society, 48(5), 519-529.

Guide Jr., V. D. R., \& van Wassenhove, L. N. (2001). Managing product returns for remanufacturing. Production and Operations Management, 10(2), 142-155.

Guide Jr., V. D. R., Teunter, R. H., \& van Wassenhove, L. N. (2003a). Matching demand and supply to maximize profits from remanufacturing. Manufacturing \& Service Operations Management, 5(4), 303-316.

Guide Jr., V. D. R., Jayaraman, V., \& Linton, J. D. (2003b). Building contingency planning for closed-loop supply chains with product recovery. Journal of Operations Management, 21(3), 259-279.

Guide Jr., V. D. R., Srivastava, R., \& Kraus, M. E. (1997a). Product structure complexity and scheduling of operations in recoverable manufacturing. International Journal of Production Research, 35(11), 3179-3199. 
Guide Jr., V. D. R., Srivastava, R., \& Spencer, M. S. (1997b). An evaluation of capacity planning techniques in a remanufacturing environment. International Journal of Production Research, 35(1), 67-82.

Guide Jr., V. D. R., Srivastava, R., \& Kraus, M. E. (1998). Proactive expediting policies for recoverable manufacturing. The Journal of the Operational Research Society, 49(5), 479-491.

Gungor, A., \& Gupta, S. M. (1999). Issues in environmentally conscious manufacturing and product recovery: a survey. Computers and Industrial Engineering, 36(4). 811-853.

Hauser, W., \& Lund, R. T. (2003). Remanufacturing: An American resource. Teaching materials on remanufacturing. Retrieved from http://www.bu.edu/reman/ RemanSlides.pdf.

Japanese Home Appliance Law. (2001). http://www.meti.go.jp/policy/recycle/main/ english /law/ home.html

Jayaraman, V. (2006). Production planning for closed-loop supply chains with product recovery and reuse: an analytical approach. International Journal of Production Research, 44(5), 981-998.

Lebreton, B. \&Tuma, A. (2006). A quantitative approach to assessing the profitability of car and truck tire remanufacturing. International Journal of Production Economics, 104(2), 639-652.

Lund, R. T. (1984a). Remanufacturing. Technology Review, 18(8), 87.

Lund, R. T. (1984b). Remanufacturing: The experience of the United States and implications for developing countries. World Bank Technical Paper, No. 31.

Maslennikova, I., \& Foley, D. (2000). Xerox's approach to sustainability. Interfaces, 30(3), 226-233.

McGovern, S. M., Surendra, M., \& Gupta, S. M. (2004). Demanufacturing strategy based upon metaheuristics. http://www.iienet.org/uploadedFiles/IIE/ Technical_Resources/ Archives/ 121.pdf

Rogers, D. S., \& Tibben-Lembke, R. S. (1999). Going Backwards:Reverse logistics trends and practices. Pittsburgh, PA: Reverse Logistics Executive Council.

Rudi, N., Pyke, D. F., \& Sporsheim, P. O. (2000). Product recovery at the Norwegian National Insurance Administration. Interfaces, 30(3), 166-179.

Schulz, T., \& Ferretti, I. (2011). On the alignment of lot sizing decisions in a remanufacturing system in the presence of random yield. Journal of Remanufacturing, 1, 3 .

Seitz, M. A. (2007). A critical assessment of motives for product recovery: the case of engine remanufacturing. Journal of Cleaner Production, 15(11-12), 1147-1157.

Souza, G. C. \& Ketzenberg, M. E. (2002). Two-stage make-to-order remanufacturing with service-level constraints. International Journal of Production Research, 40(2), 477-493.

Srivastava, R. (2004). Reusing single use devices in hospitals: A case study, in environmentally conscious manufacturing III. Edited by G. Surendra M., Proceedings of SPIE Vol. 5264 (SPIE, Bellingham, WA, 2004), 1-5.

Steinhilper, R. 1998. Remanufacturing: The ultimate form of recycling. Stuttgart: Fraunhofer IRB Verlag, D-70569.

Zussman, E., \& Seliger, G. (1999). Product remanufacturing. In Shimon Y. Nof (ed), Handbook of Industrial Robotics (2nd), New York, Wiley \& Sons. 